\title{
IMPLEMENTASI KEGIATAN RESTORASI GAMBUT DAN FENOMENA KEBAKARAN LAHAN DAN HUTAN DI DESA LUKUN, KECAMATAN TEBING TINGGI TIMUR, KABUPATEN KEPULAUAN MERANTI
}

\author{
Implementation of Peatland Restoration Activities and Phenomenonof Land and Forest Fires \\ in The Lukun Village, Tebing Tinggi Timur District, Kepulauan Meranti Regency \\ Yuli Astika $^{1^{*}}$, Nurul Qomar ${ }^{2}$, Sigit Sutikno ${ }^{3}$ \\ ${ }^{1}$ Jurusan Kehutanan, Fakultas Pertanian, Universitas Riau 28293, Pekanbaru \\ ${ }^{2}$ Dosen Jurusan Kehutanan, Fakultas Pertanian, Universitas Riau \\ ${ }^{3}$ Dosen Jurusan Teknik Sipil, Fakultas Teknik, Universitas Riau
}

Jln. Bina Widya Km 12.5 Pekanbaru, Riau 28293 Telp: 0761-63272/Fax: 0761-566821

Email:yuliastika373@gmail.com ${ }^{1}$,nqomar@lecturer.unri.ac.id ${ }^{2}$,ssutiknoyk@yahoo.com ${ }^{3}$

Diterima: 21 Juli 2021, Direvisi: 26 Juli 2021, Disetujui: 26 Januari 2022

DOI: $10.31849 /$ forestra.v17i1.7358

\begin{abstract}
Forest and land fires in Indonesia have become an annual occurrence in every dry season. The government's effort to overcome this is by issuing a peat restoration policy at the end of 2015. Although several peat restoration activities have been implemented, fires still occur every year so that they require effective handling and coordination of the implementation of peat restoration activities. This study aims to determine peatland restoration activities and the phenomenon of land and forest fires in Lukun Village, Tebing Tinggi Timur Sub District, Kepulauan Meranti Regency. The research method was carried out using a qualitative approach. Data were collected with careful observation, including detailed descriptions in context accompanied by in-depth interview notes, as well as document studies. The results show that land and forest fires occur every year, while peatland restoration activities have been carried out since 2017 including rewetting, revegetation, and revitalizing people's livelihoods, but restoration activities are not much done in land and forest prone to burning in the village while land fires and forests continue to occur in areas prone to fire.
\end{abstract}

Keywords; implementation, land and forest fires, Lukun, peatland restoration.

\section{ABSTRAK}

Kebakaran hutan dan lahan di Indonesia sudah menjadi kejadian tahunan pada setiap musim kemarau. Upaya pemerintah untuk mengatasi hal tersebut adalah dengan mengeluarkan kebijakan restorasi gambut di akhir tahun 2015. Meskipun sudah diterapkan beberapa kegiatan restorasi gambut, kebakaran 
masih saja terjadi setiap tahun sehingga memerlukan penanganan yang efektif dan koordinasi implementasi kegiatan restorasi gambut. Penelitian ini bertujuan untuk mengetahui kegiatan restorasi gambut dan fenomena kebakaran lahan dan hutan di Desa Lukun Kecamatan Tebing Tinggi Timur Kabupaten Kepulauan Meranti. Metode penelitian dilakukan dengan menggunakan pendekatan kualitatif. Data dihimpun dengan pengamatan yang seksama, mencakup deskripsi dalam konteks yang mendetail disertai catatan hasil wawancara yang mendalam, serta studi dokumen. Hasil penelitian menunjukkan bahwa kebakaran lahan dan hutan terjadi setiap tahun, sedangkan kegiatan restorasi gambut dilaksanakan sejak tahun 2017 meliputi pembuatan rewetting, revegetasi, dan revitalisasi mata pencarian masyarakat, namun kegiatan restorasi tidak banyak dilakukan di lahan dan hutan yang rawan terbakar sedangkan kebakaran lahan dan hutan terus terjadi di tempat yang rawan terbakar tersebut.

Keywords; implementasi, kebakaran lahan dan hutan, Lukun, restorasi gambut.

\section{PENDAHULUAN}

Kebakaran hutan dan lahan (karhutla) di Indonesia sudah menjadi kejadian tahunan pada setiap musim kemarau. Total kerugian yang ditanggung Indonesia sepanjang 2019 akibat kebakaran lahan dan hutan dari data Bank Dunia mencapai 5,2 miliar dollar AS. Dari luas hutan dan lahan yang terbakar di tahun 2019 setidaknya melanda delapan provinsi, yakni Kalimantan Tengah, Sumatera Selatan, Kalimantan Selatan, Riau, Kalimantan Barat, Jambi, Kalimantan Timur, dan Papua. Menurut data Dinas Lingkungan Hidup Kehutanan Provinsi Riau, karhutla di Riau tahun 2019 menjadi kejadian karhutla yang terparah setelah tahun 2015 (Tabel 1).
Tabel.1 Rekapitulasi Luas Kebakaran Hutan dan Lahan per Kabupaten Di Riau Tahun 2019

\begin{tabular}{|c|c|c|c|c|}
\hline \multirow[b]{2}{*}{ No } & \multirow[b]{2}{*}{ Kabupaten } & \multicolumn{3}{|c|}{ Luas (Ha) } \\
\hline & & 2017 & 2018 & 2019 \\
\hline 1 & Rokan Hilir & 392 & $1.985,35$ & $1.941,45$ \\
\hline 2 & Rokan Hulu & 68 & 99 & 89,25 \\
\hline 3 & Kampar & 81,25 & 127 & 385,55 \\
\hline 4 & Pekanbaru & 12,7 & 52,6 & 333,55 \\
\hline 5 & Kuansing & 24,5 & 2 & 28,1 \\
\hline 6 & $\begin{array}{l}\text { Indragiri } \\
\text { Hulu }\end{array}$ & 45,3 & 576 & $1.693,3$ \\
\hline 7 & Dumai & 122,75 & 512,25 & 351,75 \\
\hline 8 & Bengkalis & 64 & 576,95 & $1.911,34$ \\
\hline 9 & $\begin{array}{l}\text { Kepulauan } \\
\text { Meranti }\end{array}$ & 236,11 & 963,56 & 388,5 \\
\hline 10 & Siak & 76,5 & 157,25 & 891,19 \\
\hline 11 & Pelelawan & 164,16 & 266,5 & 561,2 \\
\hline 12 & $\begin{array}{l}\text { Indragiri } \\
\text { Hilir }\end{array}$ & 82 & 458 & $1.138,35$ \\
\hline
\end{tabular}

Sumber : DLHK Provinsi Riau 
Indonesia mempunyai lahan gambut 24,14 juta hektar dan menjadi negara ke empat dengan luasan gambut terluas di dunia. Jumlah tersebut tersebar di beberapa wilayah, sekitar 9,16 juta hektar berlokasi di Sumatera, 8,39 juta hektar di Kalimantan, 60 ribu hektar di Sulawesi, dan 6,53 juta hektar di Papua (Sugiyanto, 2019). Namun, lahan gambut yang terdapat di Provinsi Riau kini mengalami kritis akibat kebakaran hutan dan lahan yang terjadi beberapa tahun belakangan ini. Permasalahan kebakaran hutan dan lahan ini telah menjadi isu nasional bahkan internasional yang patut mendapat perhatian khusus oleh pemerintah.

Dampak dari kebakaran hutan dan lahan yang terjadi sangat besar, terutama ketika terjadi di lahan gambut (Monde et al., 2008). Kebakaran hutan dan lahan gambut secara nyata menyebabkan terjadinya degradasi kondisi lingkungan, gangguan terhadap kesehatan manusia, dan gangguan terhadap ekonomi dan sosial. Upaya pemerintah untuk mengatasi hal tersebut adalah dengan mengeluarkan kebijakan restorasi gambut di akhir tahun 2015. Ada tiga sasaran yang ingin dicapai melalui kebijakan tersebut, yaitu: (1) pemulihan hidrologi, vegetasi, dan daya dukung sosial-ekonomi pada ekosistem gambut yang terdegradasi; (2) perlindungan ekosistem gambut bagi penyangga kehidupan; dan (3) penataan ulang pengelolaan(pemanfaatan) ekosistem gambut secara berkelanjutan.

Desa Lukun merupakan salah satu dari 75 desa yang menjadi target restorasi gambut di 7 provinsi sejak tahun 2017 yang disusun oleh Badan Restorasi Gambut. Kebakaran yang terjadi telah menimbulkan dampak serius bagi alam serta lingkungan sosial setempat. Selain membuat sebagian masyarakat kehilangan mata pencaharian, kebakaran juga telah menyebabkan terjadinya migrasi fauna dan matinya tumbuhan serta membuat lahan gambut di Desa Lukun menjadi kritis bahkan sempat mengalami kekeringan (Sugiyanto, 2019).

Meskipun sudah diterapkan beberapa kegiatan restorasi gambut sejak tahun 2017 hingga 2019, kebakaran masih saja terjadi setiap tahun sehingga memerlukan penanganan yang efektif dan koordinasi implementasi kegiatan restorasi gambut, 
sehingga permasalahan tersebut dapat dicegah dan diselesaikan agar tidak terjadi pada tahuntahun berikutnya. Berdasarkan permasalahan di atas maka perlu dilakukan penelitian mengenai implementasi kegiatan restorasi gambut dan fenomena kebakaran hutan dan lahan di Desa Lukun Kabupaten Kepulauan Meranti. Tujuan penelitian ini adalah mengetahui kegiatan restorasi gambut dan fenomena kebakaran lahan dan hutan di Desa Lukun Kecamatan Tebing Tinggi Timur Kabupaten Kepulauan Meranti.

\section{METODOLOGI}

Penelitian ini telah dilaksanakan pada bulan Oktober sampai Desember 2020. Penelitian ini berlokasi di Desa Lukun, Kecamatan Tebing Tinggi Timur di Kabupaten Kepulauan Meranti. Bahan yang digunakan yaitu laporan kegiatan restorasi gambut meliputi kegiatan yang dilakukan oleh :1) BRG melalui Deputi 2, Deputi 3, dan Deputi 4, dan 2) bantuan perusahaan sekitar, data temuan kasus kebakaran hutan dan lahan dalam bentuk peta, sebaran hotspot, luas lahan terbakar serta dokumen-dokumen yang terkait dengan penelitian yang didapat dari instansi pemerintah dan legislatif. Alat yang digunakan yaitu berupa panduan pertanyaan untuk wawancara mendalam, seperangkat komputer yang didukung oleh perangkat lunak Microsoft Excel 2010, alat perekam suara, kamera dan alat tulis.

Teknik wawancara yang digunakan pada penelitian ini yaitu wawancara mendalam kepada informan yang ditentukan berdasarkan snowball sampling sehingga didapatkan informasi yang lengkap dan akurat untuk menjawab tujuan penelitian. Wawancara mendalam dilakukan dengan menggunakan daftar pertanyaan. Beberapa pihak terkait yang menjadi informan adalah 1) Staf Kerjasama Teknis Kedeputian Perencanaan dan Kerjasama Badan Restorasi Gambut dari Jakarta, 2) Kasi Pemadaman Kebakaran Pemukiman Penduduk dan Gedung BPBD Bidang DAMKR, 3) Penelaah Data Pengukuran dan Pengujian Hasil Hutan Kayu Di KPH Tebing Tinggi, 4) Kepala Humas PT NSP, 5) Pemerintah Desa Lukun, 6) Ketua Lembaga Pengelola Hutan Desa, dan 7) Masyarakat yang diwakili oleh Masyarakat Peduli Api (MPA). Selain melakukan wawancara mendalam, juga dilakukan 
observasi atau pengamatan langsung di beberapa lahan yang sering terbakar, yaitu di Pantuk, Pelampin, dan di PT. NSP.

Seiring dengan pengumpulan data primer, dilakukan pengumpulan data sekunder berupa dokumen atau laporan kegiatan restorasi gambut. Kegiatan restorasi gambut meliputi kegiatan yang dilakukan oleh : 1) BRG melalui Deputi 2, Deputi 3, dan Deputi 4, dan 2) bantuan perusahaan sekitar, serta laporan kegiatan penanggulangan kebakaran hutan dan lahan dari pihak terkait dan hasil hasil penelitian terkait. Proses pengumpulan data primer dan data sekunder ini dapat berulang dan berbalik untuk saling melengkapi dan mengkonfirmasi.

\section{HASIL DAN PEMBAHASAN}

\subsection{Kondisi Umum Desa Lukun}

Desa Lukun termasuk dalam wilayah Kesatuan Hidrologis Gambut (KHG) Pulau Tebing Tinggi yang terletak di Kabupaten Kepulauan Meranti. Kabupaten Kepulauan Meranti memiliki empat pulau besar, yaitu Pulau Padang, Pulau Merbau, Pulau Rangsang, dan Pulau Tebing Tinggi. Pulau Tebing Tinggi memiliki tiga kecamatan, yaitu
Kecamatan Tebing Tinggi, Kecamatan Tebing Tinggi Timur, dan Kecamatan Tebing Tinggi Barat. Daratan di Pulau Tebing Tinggi Timur didominasi oleh lahan gambut.

Desa Lukun merupakan salah satu desa yang terletak di Kecamatan Tebing Tinggi Timur, Kabupaten Kepulauan Meranti, Provinsi Riau (Gambar 1). Desa Lukun memiliki jarak ke kantor kecamatan di Sungai Tohor sekitar $12 \mathrm{~km}$. Desa Lukun memiliki luas 1.546 ha dengan jumlah penduduk 523 Kepala Keluarga dan 1.888 jiwa, terdiri dari 988 laki-laki dan 900 perempuan (Tabel 2). Desa Lukun terbagi dalam 5 dusun, $10 \mathrm{RW}$, dan 20 RT.

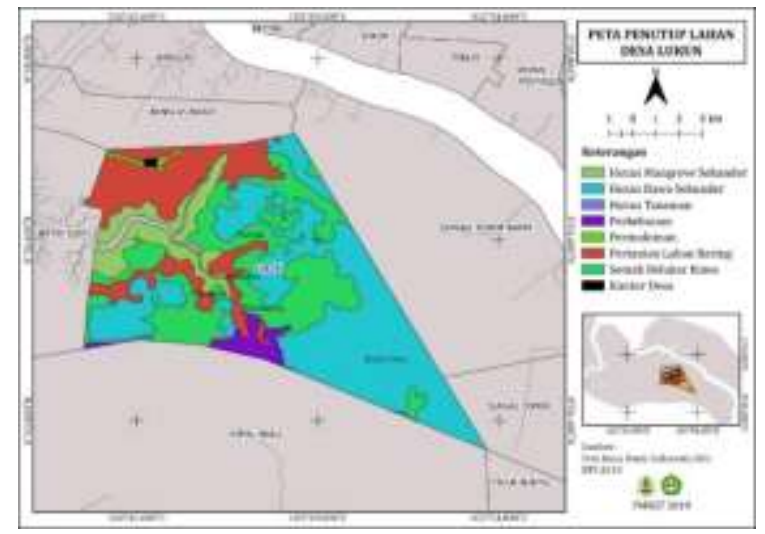

Gambar 1. Peta Penutup Lahan Desa Lukun (Sumber: PMRGT, 2019) 
Tabel 2. Penduduk Desa Lukun Menurut Jenis Kelamin Tahun 2020

\begin{tabular}{llrr}
\hline No & Jenis Kelamin & \multicolumn{1}{c}{$\begin{array}{c}\text { Jumlah } \\
\text { (jiwa) }\end{array}$} & $\begin{array}{r}\text { Persentase } \\
(\%)\end{array}$ \\
\hline 1 & Laki-laki & 988 & 52,33 \\
2 & Perempuan & 900 & 47,66 \\
\multicolumn{2}{l}{ Sumber: Kantor Desa Lukun (2020) }
\end{tabular}

\subsection{Kegiatan Restorasi Gambut di Desa}

\section{Lukun}

Masyarakat dan berbagai instansi pemerintah maupun LSM telah berkontribusi terhadap permulihan gambut di Desa Lukun dengan berbagai macam kegiatan restorasi. Kegiatan restorasi gambut yang dilakukan sejak tahun 2017 telah memberikan dampak yang positif terhadap masyarakat dan meningkatkan kesadaran akan pentingnya menjaga lingkungan. Beberapa instasi mempunyai program terkait dengan restorasi melalui pendekatan 3R, yakni rewetting (pembasahan kembali), revegetasi (penanaman kembali), dan revitalisasi mata pencaharian (upaya pemaksimalan sumber ekonomi masyarakat) melalui potensi yang ada di wilayah setempat. a. Rewetting (pembasahan kembali)

Kebakaran hutan dan lahan dapat merugikan masyarakat untuk itu lahan gambut perlu dijaga dan dirawat keberadaannya dengan berbagai cara. Namun hal yang paling penting adalah menjaga agar lahan gambut tetap lembab dan basah. Salah satu kegiatan pembasahan gambut yang dilakukan di Desa Lukun adalah pembuatan sekat kanal. Sekat kanal adalah bangunan air berupa sekat yang dibangun di badan kanal buatan yang telah ada di lahan gambut yang bertujuan untuk menaikkan daya simpan (retensi) air pada badan kanal serta mengurangi atau mencegah penurunan permukaan air di lahan gambut sehingga lahan gambut di sekitarnya tetap basah dan sulit terbakar (Badan Restorasi Gambut, 2017).

Pembuatan sekat kanal secara sederhana adalah untuk menahan laju air atau membendung air agar tidak sepenuhnya keluar mengalir ke sungai dan laut. Hal ini sejalan dengan pernyataan Yuliani (2017) bahwa sekat kanal berfungsi untuk menahan derasnya aliran air dari kubah gambut ke bawah, dan mengarahkan aliran air ke samping. 


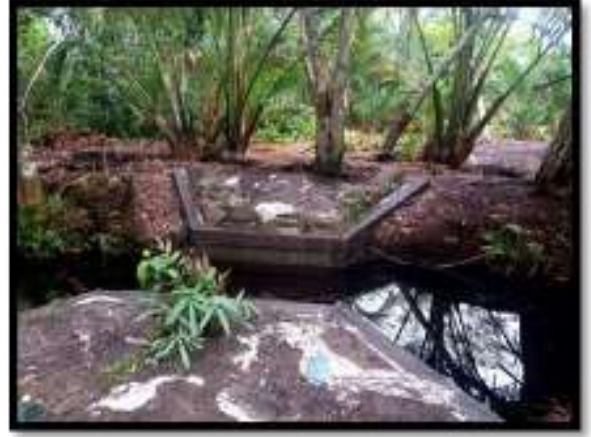

Gambar 2. Kondisi Sekat Kanal di Desa Lukun

b. Revegetasi (penanaman kembali)

Revegetasi adalah upaya pemulihan tutupan lahan pada ekosistem gambut melalui penanaman jenis tanaman asli pada fungsi lindung ekosistem gambut atau dengan jenis tanaman lain yang adaptif terhadap lahan basah dan memiliki nilai ekonomi pada fungsi budidaya. Gambut adalah jenis tanah yang memiliki keasaman yang tinggi sehingga diperlukan perlakuan khusus dalam melakukan revegetasi. Tanaman sagu merupakan jenis tanaman populer di Desa Lukun dan merupakan salah satu komoditas pilihan untuk revegetasi karena penanamannya yang sederhana dan tidak membutuhkan banyak perawatan. Hal ini sesuai dengan pernyataan Bintoro, et al. (2008) bahwa tanaman sagu dapat tumbuh pada berbagai kondisi hidrologi dari yang terendam air sampai ke lahan yang tidak terendam air.

Masyarakat Desa Lukun melakukan revegetasi dengan sistem paludikultur. Paludikultur berasal dari bahasa latin (palus) berarti rawa. Paludikultur berarti penggunaan lahan rawa (dan rawa gambut) secara produktif dengan cara-cara melindungi gambut. (Joosten, et al. 2012). Kegiatan paludikultur yang telah diterapkan merupakan upaya restorasi dan rehabilitasi ekosistem rawa gambut yang terdegradasi, terutama akibat pembukaan kanal/drainase serta kebakaran hutan pada lahan gambut. Praktik paludikultur yang diterapkan secara tradisional oleh masyarakat lokal adalah praktik budidaya tanaman yang telah beradaptasi di rawa dan rawa gambut seperti budidaya tanaman sagu.

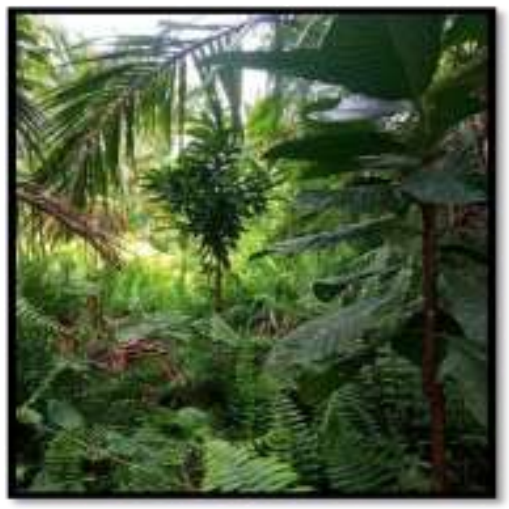

Gambar3. Tanaman sela di Perkebunan Sagu 
Pada tahun 2017 dan 2018 Pusat Studi Bencana dan Badan Restorasi Gambut telah melakukan riset aksi dengan membuat plot percontohan paludikultur di lahan masyarakat. Selain sistem budidaya paludikultur juga diterapkan sistem agroforestri di Desa Lukun (Qomar, et al. 2017).

\section{c. Revitalisasi Sumber Mata Pencarian}

Revitalisasi sumber mata pencarian merupakan kegiatan yang dilakukan di Desa Lukun. Revitalisasi sumber-sumber mata pencarian masyarakat bertujuan untuk meningkatkan kesejahteraan masyarakat yang ada di dalam dan sekitar areal restorasi gambut(Badan Restorasi Gambut, 2017). Pada tahun 2018 Desa Lukun memproleh bantuan program penanaman sagu melalui pendekatan R3 dari dana APBN BRG RI.

Berdasarkan hasil wawancara dengan Pak Amran selaku ketua Lembaga Pengelola Hutan Desa Lukun bahwa kegiatan budidaya penanaman sagu ini diperuntukkan untuk masyarakat Desa Lukun. Hal ini karena masyarakat di Desa Lukun masih banyak melakukan kegiatan penebangan kayu untuk memenuhi kebutuhan sehari-hari. Sebelum adanya bantuan tanaman sagu masyarakat Desa lukun sudah ada beberapa yang melakukan penanaman namun penanaman tanaman sagu tidak begitu mendapatkan perhatian dan perawatan. Oleh karena itu kegiatan budidaya tanaman sagu diharapkan dapat mengubah kebiasaan masyarakat sebelumnya. Menurut Basir (2016), faktor yang menyebabkan terjadinya penebangan kayu adalah tidak tersedianya lapangan pekerjaan dan faktor kemiskinan.

\section{d. Desa Peduli Gambut}

Desa Peduli Gambut adalah kerangka penyelaras untuk program-program pembangunan yang ada di perdesaan gambut, khususnya di dalam dan sekitar areal restorasi gambut. Kegiatan Pembinaan Desa Peduli Gambut (DPG) merupakan kegiatan pembinaan terhadap masyarakat desa yang kegiatan usaha ekonominya terimbas dengan kegiatan Kegiatan Restorasi Gambut berupa rewetting dan revegetasi (Ramdhan \& Siregar, 2018). Program ini dilaksanakan oleh Deputi 3 BRG. Pendekatan yang digunakan adalah merajut kerjasama antar desa yang ada dalam satu bentang alam Kesatuan Hidrologis Gambut. Pembentukan kawasan perdesaan 
gambut menjadi pintu masuk bagi perencanaan pengelolaan gambut oleh desa.

Program Desa Peduli Gambut meliputi kegiatan fasilitasi pembentukan kawasan perdesaan, perencanaan tata ruang desa dan kawasan perdesaan, identifikasi dan resolusi konflik, pengakuan dan legalisasi hak dan akses, kelembagaan untuk pengelolaan hidrologi lahan, kerjasama antar desa, pemberdayaan ekonomi, penguatan pengetahuan local dan kesiapsiagaan masyarakat desa dalam menghadapi bencana kebakaran gambut.

Menurut Bapak Syahrudin selaku Pendamping Program Desa Peduli Gambut di Desa Lukun tahun 2017, kegiatan-kegiatan yang dilaksanakan yaitu sosialisasi, edukasi masyarakat, pelatihan Badan Usaha Milik Desa, dan penguatan MPA. Kebakaran Hutan dan Lahan di Desa Lukun.

\subsection{Kebakaran Hutan dan Lahan di Desa Lukun}

Menurut Narasumber, kebakaran hutan dan lahan di Desa Lukun terjadi hampir setiap tahun, mulai tahun 2014 sampai tahun 2019. Jumlah hotspot periode tahun 2014-2019 di
Desa Lukun dapat dilihat pada Tabel 3. Kebakaran hutan dan lahan yang terjadi di Desa Lukun berdasarkan hasil wawancara dengan masyarakat disebabkan oleh kekeringan lahan gambut akibat kanal-kanal yang dibuat dan ditinggalkan oleh masyarakat untuk mengangkut kayu tebangan liar pada tahun 2000-an. Kebakaran sering terjadi berulang di daerah Pantuk, Pelampin, dan Ulu Mamut.

Tabel 3. Jumlah hotspot periode tahun 2014-2019 di Desa Lukun

\begin{tabular}{lrr}
\hline Tahun & Jumlah Hotspot & \\
\hline 2014 & 428 \\
2015 & 1 \\
2016 & 0 \\
2017 & 1 \\
2018 & 203 \\
2019 & 256 \\
\hline Jumlah & \\
\hline
\end{tabular}

Berdasarkan hasil wawancara secara umum, penyebab kebakaran di Desa Lukun juga dikarenakan kegiatan penyiapan lahan yang dilakukan dengan cara pembakaran oleh masyarakat yang bisa merambat sampai pada areal perusahaan. Kebiasaan masyarakat melakukan pembersihan lahan dengan cara bakar untuk mempercepat proses pembersihan 
lahan areal pertanian dan perkebunan menjadi pemicu terjadinya kebakaran lahan. Hal ini diyakini masyarakat bahwa dengan cara pembakaran lebih mudah, murah dan waktu yangdigunakan singkat. Selain karena faktor kesengajaan, penyebab kebakaran di Desa Lukun juga disebabkan akibat kelalaian atau kecerobohan masyarakat yang dalam menggunakan api di musim kemarau yang panjang.

Hal ini juga sesuai dengan hasil studi (Suhendra, et al., 2019), bahwa kejadian kebakaran hutan dan lahan di Desa Lukun merupakan aktivitas penggunaan api dalam bentuk pembukaan lahan secara sengaja maupun ketidaksengajaan. Desa Lukun merupakan kawasan dengan tingkat kedalaman gambut lebih dari $3 \mathrm{~m}$ sehingga sangat berpotensi terjadinya kebakaran hutan dan lahan. Selain itu, penebangan liar (illegal logging), lemahnya tata kelola air serta rendahnya penyuluhan tentang pencegahan karhutla kepada masyarakat juga menjadi salah satu faktor penyebab terjadinya kebakaran hutan dan lahan.

Menurut penuturan masyarakat setempat, kebakaran di Desa Lukun terjadi di lokasi yang jauh dari kampung yang jarang didatangi orang ( Gambar 4). Kebakaran terjadi di seberang sungai dari pemukiman. Kebakaran pernah terjadi di daerah Pantuk namun masih bisa cepat ditanggulangi oleh masyarakat karena lokasi kebakaran agak dekat dengan jalan dan terdapat sekat kanal sehingga mudah dalam pengambilanair untuk memadamkannya.

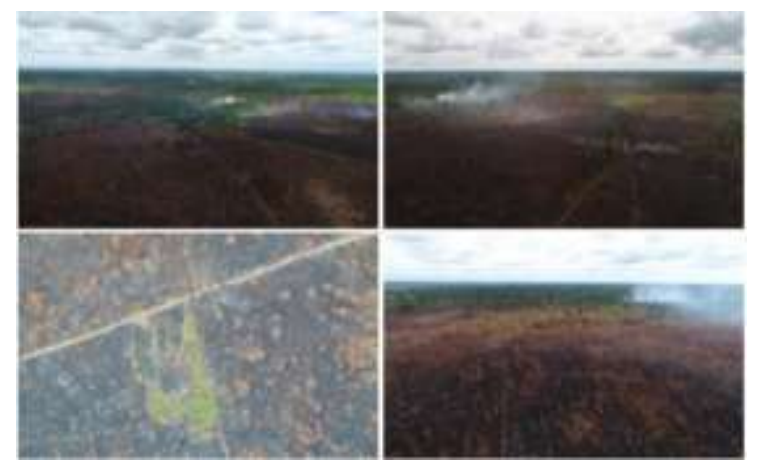

Gambar 4. Kebakaran di Ulu Mamud tahun 2018 Sumber: Jalil 2018

Kebakaran lahan dan hutan sering terjadi di area yang jauh dari pemukiman sehingga masyarakat terlambat mendapatkan informasi ketika api sudah menjalar luas. Penanggulangan kebakaran pun sulit dipadamkan karena lokasi kebakaran yang sulit dijangkau, dimana untuk menuju lokasi kebakaran harus mengarungi sungai ke arah hulu yang masih dipengaruhi oleh pasang surut 
air laut.Karena lokasi kebakaran sangat jauh dari pemukiman, masyarakat terpaksa menginap di dalam hutan pada saat terjadi kebakaran dan sulit membawa peralatan pemadam kebakaran.

Berdasarkan Gambar 5 dapat dilihat bahwa titik panas (hotspot) tersebar sangat jauh dari lokasi pemukiman. Lokasi kebakaran terjadi di lahan perkebunan masyarakat, semak belukar, pertanian lahan kering, dan tanah terbuka. Ada beberapa sekat kanal kayu yang dibuat di dekat lokasi bekas terbakar, namun lebih banyak yang dibuat di dekat lokasi permukiman dan perkebunan masyarakat, yakni di sekitar Jalan Lukun Sungai Tohor.

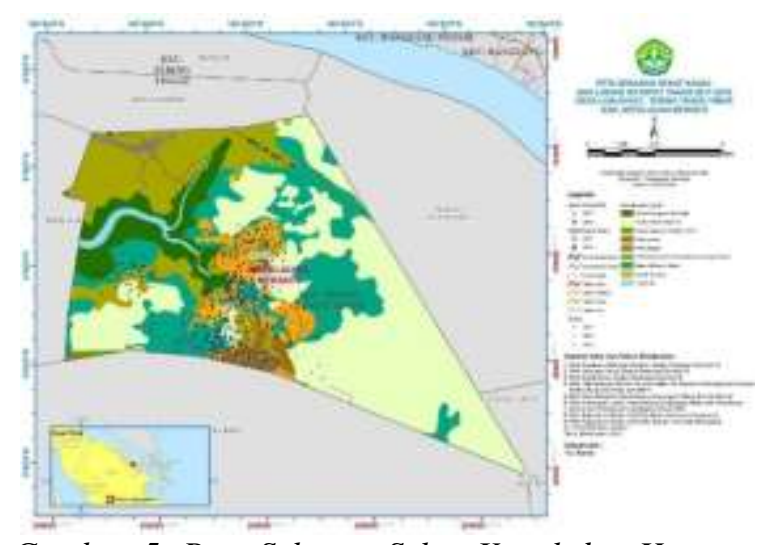

Gambar 5. Peta Sebaran Sekat Kanal dan Hotspot tahun 2017-2019 di Lukun
Sekat kanal riset dan percontohan dibuat oleh Pusat Studi Bencana melalui anggaran Deputi 4 BRG tahun 2017-2018 dibuat di sekitar pemukiman/perkebunan warga agar masyarakat bisa mempelajari dan mencontoh bagaimana kinerja sekat kanal dalam membasahi lahan kembali, sekaligus untuk mencegah kebakaran di sekitar pemukiman dan kebun warga. Sekat kanal kayu yang dibuatoleh Kelompok Masyarakat (Pokmas) dengan anggaran dari APBN melalui Tugas Perbatuan Deputi 2 BRG tahun 2018 sebagian besar berada pada kanal yang samadan dekat dengan posisi sekat kanal dari PSB UNRI Deputi 4, yakni di pinggir Jalan Lukun Sungai Tohor.

Berdasarkan wawancara dengan Pak Amran, pembuatan sekat kanal terjadi ketidaksingkronan antara BRG dengan pemerintah kabupaten. Beberapa pihak di kabupaten merasa tersinggung karena beberapa kegiatan restorasi gambut tidak dikoordinasikan. Pihak kabupaten tidak pernah datang dalam kegiatan restorasi karena kegiatan restorasi biasanya dilaksanakan oleh Kelompok Masyarakat (Pokmas) yang dikoordinir langsung oleh 
BRG atau TRGD Provinsi Riau yang langsung datang ke Desa Lukun.

\subsection{Dampak Kebakaran Hutan dan Lahan}

Dampak kebakaran hutan dan lahan di

Desa Lukun bagi manusia dan ekosistem sangat mempengaruhi lingkungan baik secara langsung maupun tidak langsung. Kebakaran hutan dan lahan berdampak pada sosial ekonomi, dan ekosistem gambut itu tersendiri. Menurut (Andria et al., 2010) kebakaran hutan dan lahan mengakibatkan kerusakan hutan dan hasil hutan serta menimbulkan kerugian ekonomis, ekologis, dan sosial. Berdasarkan hasil wawancara mendalam dengan beberapa informan, bahwa fenomena kebakaran yang terjadi di Desa Lukun terjadi dan membuat banyak permasalahan yang harus diselesaikan.

\section{a. Dampak terhadap sosial ekonomi}

Kebakaran hutan dan lahan yang terjadi berdampak kepada banyak sektor, sektor kesehatan, lingkungan, perekonomian, dan transportasi. Kebakaran hutan dan lahan menyebabkan banyak sekolah yang diliburkan, Bapak Asyari selaku ketua MPA mengatakan bahkan sampai negara tetangga merasakan dampak darikebakaran hutan dan lahan. Anak-anak Desa Lukun banyak yang bersekolah di Selat Panjang, pada saat kabut asap mereka terpaksa libur sekolah karena kempang, alat transportasi laut untuk menyeberangi Selat Suir, tidak beroperasi/jalan karena jarak pandang terhalang oleh kabut asap.

Pasca kebakaran hutan dan lahan, masyarakat Desa Lukun mengalami perubahan mulai timbul rasa kepedulian terhadap kelestarian gambut, setelah kebakaran mereka sedikit mengetahui dan belajar apa itu gambut, mereka juga ikut berkontribusi terhadap kegiatan-kegiatan restorasi gambut dan bergabung di Masyarakat Peduli Api.

b. Dampak terhadap ekosistem gambut

Pasca kebakaran hutan dan lahan banyak flora dan fauna yang mati, terjadi ketidakseimbangan ekosistem gambut. Lahanlahan bekas kebakaran menyisakan tunggultunggul kayu dan ditumbuhi tanaman pakupakuan dapat dilihat pada Gambar 6. Pohonpohon yang hangus terbakar. Binatangbinatang pun banyak yang berpindah karena kehilangan tempat tinggal mereka. 


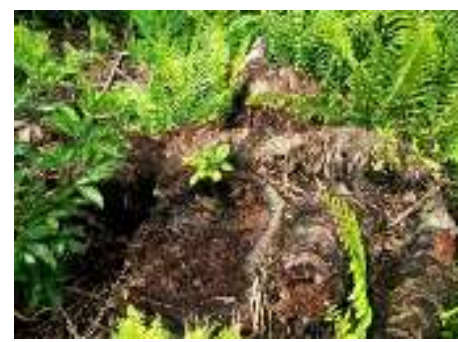

Gambar 6. Tunggul tanaman sagu bekas terbakar

Gangguan terhadap ekosistem gambut telah menimbulkan dampak yang cukup parah dilihat pada kebun-kebun masyarakat di Lukun. Karena keringnya lahan gambut mengakibatkan pertumbuhan tanaman sagu mereka terkendala. Menurut masyarakat setempat, hal ini mengakibatkan daun tanaman sagu tidak tumbuh subur sehingga batang Sagu tidak terlalu tinggi dan berdiameter kecil. Mengeringnya lahan gambut pada kebun karet menyebabkan permukaan tanah menjadi turun dan menurunkan produktifitas tanaman. Perakaran pohon karet yang muncul ke permukaan tanah membuktikan adanya penurunan tanah yang terjadi dari waktu ke waktu di Desa Lukun.

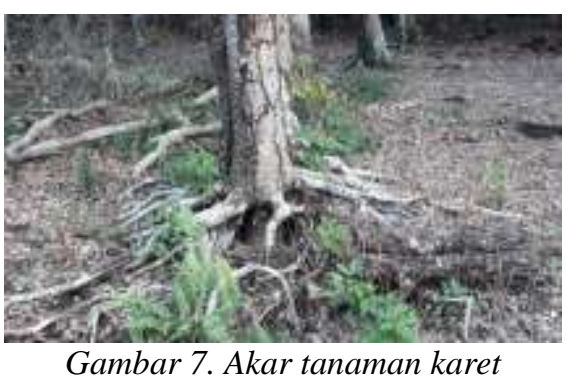

3.5 Penanggulangan Kebakaran Hutan dan Lahan

Penanggulangan kebakaran hutan dan lahan di Desa Lukun melibatkan banyak elemen baik dari masyarakat/MPA, Pemerintah, dan juga bantuan dari swasta/perusahaan. Penanggulangan kebakaran lahan dan hutan di Desa Lukun melibatkan banyak pihak yang langsung turun kelapangan. Masyarakat dan MPA berantusias untuk memadamkan api, ketika musim kemarau MPA bergantian untuk patroli di sekitar hutan bahkan sampai tidur di dalam hutan ketika memadamkan api. Peralatan pemadam kebakaran yang tersedia di Desa Lukun terdapat 4 buah mesin robin air dan selangnya, posko karhutla, dan radio AT.

Berdasarkan hasil wawancara dengan pihak PT NSP untuk pengendalian kebakaran hutan dan lahan mereka mengacu pada Permen LHK No. 
15 Maret 2016 Tentang Pengendalian Kebakaran Hutan dan Lahan. Strategi pengendalian kebakaran hutan dan lahan di PT NSP adalah sebagai berikut:

a. Pengorganisasian dan Pengelolaan Sumberdaya Manusia

Strategi yaitu membentuk organisasi Brigdalkarhutla setelah terbentuk dilaksanakan Diklat Dalkarhutla kemudian melakukan latihan bersama regu Brigdalkarhutla dan MPA dengan simulasi bagaimana pengendalian kebakaran hutan dan lahan.

b. Pengelolaan Sarpras Dalkarhutla

Mengantisipasi dan menanggulangi kebakaran hutan dan lahan dibutuhkan pengelolaan sistem, sarana, dan prasarana pengendalian kebakaran hutan dan lahan dilakukan secara terkoordinasi. Perusahaan mempunyai menara api dan posko jaga. Perusahaaan juga memberikan bantuan mesin pompa air PMK 1 unit untuk Desa Lukun.

\section{c. Pencegahan dan Deteksi Dini}

Menurut Pak Budi selaku Humas PT NSP, pada musim kemarau ada dua orang bertugas setiap dua jam sekali untuk patroli, dan saat ada api dari pos terdekat siap turun untuk memadamkan api.

d. Pemadaman Kebakaran

Jika terjadi kebakaran di wilayah PT NSP maupun desa tetangga, seperti Desa Lukun, pihak perusahaan akan membantu memadamkan api bersama masyarakat setempat karena takut api menjalar masuk ke wilayah perusahaan. PT NSP memberikan bantuan berupa mesin pompa pemadam kebakaran untuk Desa Lukun.

e. Penanganan Pasca Kebakaran

Penanganan pasca kebakaran PT NSP membantu 10.000 bibit Sagu pada tahun 2015. Bibit sagu diberikan kepada mayarakat sebagai upaya untuk revegetasi lahan bekas terbakar di Desa Lukun.

f. Tata kelola Air

Tata kelola air di area PT NSP pada dasarnya menjaga level air dekat dengan muka tanah, karena tanaman sagu dalam pertumbuhannyaa sangat menyukai kondisi berair. Untuk menjaga keseimbangan air di kawasan PT NSP dibuat kanal-kanal dan sekat kanal/DAM. Sekat kanal/DAM berfungsi untuk menjaga/ menahan air keluar dari dalam kawasan PT NSP. Pemasangan sekat kanal dilakukan di batas-batas tempat keluarnya air 
dan pada area dengan ketinggian yang berbeda untuk menjaga tinggi muka air tanah $<40 \mathrm{~cm}$ dari permukaan tanah. Jumlah sekat kanal yang ada dalam kawasan PT NSP saat ini 152 unit.

\section{KESIMPULAN DAN SARAN}

\section{A. Kesimpulan}

Kebakaran lahan dan hutan di Desa Lukun terjadi setiap tahun mulai tahun 20142019 meskipun kegiatan restorasi gambut sudah dilaksanakan sejak tahun 2017 meliputi kegiatan rewetting, revegetasi, dan revitalisasi mata pencarian masyarakat, karena kegiatan restorasi tidak terlalu banyak dilakukan di lahan dan hutan yang rawan terbakar.

\section{B. Saran}

Diperlukan kerjasama antara masyarakat dan pemerintah setempat untuk menjaga dan memelihara sekat kanal dan aset kegiatan restorasi gambut lainnya.

\section{DAFTAR PUSTAKA}

Andria, A. Y., Barus, B., \& Nasdian, F. T. (2010). Keterkaitan Faktor Biofisik dan Penguasaan Lahan Hutan Dengan Kerawanan Kebakaran Hutan Dalam Perspektif Penataan Ruang: Studi Kasus
Pada Wilayah HTI di Jambi. Jurnal Ilmu Tanah Dan Lingkungan, 12(1), 15-22.

Badan Restorasi Gambut. (2017). Rencana Strategis Restorasi Gambut 2016-2020.

Basir, M. A. (2016). Upaya Pemerintah Dalam Menangani Illegal Loging (Studi Pada UPTD Kehutanan Kecamatan Kulisusu Kabupaten Buton Utara). Kybernan: Jurnal Studi Kepemerintahan, 1(2), 3847.

Bintoro, M. H., N. Setiadi, D. Allorerung, W. Y. Mofu, dan A. P. (2008). Pembibitan dan Karakteristik Lingkungan Tumbuh Tanaman Sagu.

Joosten, H., Dommain, R., Haberl, A., Peters, J., Silvius, M., \&Witcmann, W. (2012). Implementation.In: Joosten, H., TapioBistorm, M.L., \& Tol, S. (eds). Peatlandsguidance for climate change mitigation through convservation and sustainable use.

Monde, A., Sinukaban, N., Murtilaksono, K., \& Pandjaitan, N. (2008). Dinamika karbon (C) akibat alih guna lahan hutan menjadi lahan pertanian. Agroland: Jurnal Ilmu-Ilmu Pertanian, 15(1).

Qomar, N. A. Muhammad, Idwar, Isnaini, dan A. Rony. (2017). Pengembangan Model Lahan Gambut Berskala Kecil yang Produktif dan Ramah Lingkungan di KHG Pulau Tebing Tinggi Kabupaten Kepulauan Meranti Provinsi Riau.Laporan Akhir BRG.

Ramdhan, M., \& Siregar, Z. A. (2018). Pengelolaan wilayah gambut melalui 
pemberdayaan masyarakat desa pesisir di kawasan hidrologis gambut Sungai Katingan dan Sungai Mentaya Provinsi Kalimantan Tengah. In Jurnal Segara (Vol. 14, Issue 3).

Sugiyanto, S. (2019). Kearifan Lokal Petani dan Kelestarian Gambut (Studi kasus Desa Lukun Kecamatan. JOM FISIP, 6(1), 4-5.

Suhendra, M. Suhada, N. Shafitri, D,K. Damanik, P, C. K. (2019). Aksi Live In di lokasi Desa gambut Program Peneliti Muda Restorasi Gambut Tropika (PMRGT).

Yuliani, F. (2017). Pelaksanaan cannal blocking sebagai upaya restorasi gambut di Kabupaten Meranti Provinsi Riau. Spirit Publik: Jurnal Administrasi Publik, 12(1), 69-84. 